\title{
Consumer Perceptions, Behaviors, and Knowledge of Food Waste in a Rural American State
}

\author{
Selena Ahmed ${ }^{1}$, Alyssa Stewart ${ }^{1}$, Erin Smith ${ }^{1}$, Teresa Warne ${ }^{1}$ and \\ Carmen Byker Shanks ${ }^{1,2 *}$ \\ ${ }^{1}$ Food and Health Lab, Department of Health and Human Development, Montana State University, Bozeman, MT, \\ United States, ${ }^{2}$ Gretchen Swanson Center for Nutrition, Omaha, NE, United States
}

\section{OPEN ACCESS}

Edited by:

Elena Kovtun

National University of Life and

Environmental Sciences of

Ukraine, Ukraine

Reviewed by:

Catia Grisa,

Federal University of Rio Grande do

Sul, Brazil

C. K. Sunil,

Indian Institute of Food Processing

Technology, India

${ }^{*}$ Correspondence:

Carmen Byker Shanks

cbykershanks@montana.edu

Specialty section

This article was submitted to

Sustainable Food Processing,

a section of the journal

Frontiers in Sustainable Food Systems

Received: 01 July 2021

Accepted: 20 August 2021

Published: 23 September 2021

Citation:

Ahmed S, Stewart A, Smith E,

Warne T and Byker Shanks C (2021) Consumer Perceptions, Behaviors, and Knowledge of Food Waste in a

Rural American State.

Front. Sustain. Food Syst. 5:734785.

doi: 10.3389/fsufs.2021.734785
Understanding consumer knowledge, attitudes, and behaviors towards food waste is critical for informing evidence-based programs to advance sustainable food systems. A lack of knowledge regarding consumer food waste at the local level limits the ability to inform place-based solutions that are locally relevant. We administered an online survey to examine consumer perceptions, behaviors, and knowledge of food waste at the household level in Montana, a rural state in the United States. The majority of surveyed participants (58\%) reported that they waste $10 \%$ or less of procured food. Almost half the participants (48\%) are willing to take additional action to reduce food waste. Social factors including guilt and setting a good example were found to be greater motivators for reducing food waste compared to economic and environmental factors. Most survey participants (80\%) perceive it would not be difficult to notably reduce their household's food waste. Overall, participants' reporting of their household's food waste quantity is lower than national quantities while their willingness to reduce food waste was higher than findings from a national survey. This study highlights the need for place-based solutions that are locally relevant to reduce household food waste towards enhancing the sustainability of food systems for supporting planetary health.

Keywords: food waste, household behavior, sustainability, food systems, place-based solutions, community education, consumer perceptions

\section{INTRODUCTION}

Food waste is a major challenge for advancing sustainable food systems with environmental, economic, social, and health implications. Globally, an estimated $30-50 \%$ of all food produced is wasted (Food and Agriculture Organization, 2009; Fox and Fimeche, 2013; Gunders et al., 2017). Food waste occurs throughout the food supply chain from agricultural production, postharvest handling, storage, and processing to distribution and consumption (Food and Agriculture Organization, 2015). Generally, the majority of food waste in low-income countries occurs due to technical limitations at the storage, processing, and distribution levels while occurring at the consumption level in medium and high-income countries (Food and Agriculture Organization, 2015). For example, in the United States, over $30 \%$ of the national food supply is lost at the retail and consumer levels (Buzby et al., 2014), with some estimates of post-harvest food waste as high as $40 \%$ (Hall et al., 2009; Neff et al., 2015). It is thus critical to understand consumer knowledge, attitudes, and behaviors regarding food waste in order to inform evidence-based programs for reducing food waste towards enhancing the sustainability of food systems for supporting planetary health. 
On an environmental basis, $\sim 24 \%$ of freshwater used in crop production, $23 \%$ of cropland area, and $23 \%$ of fertilizer use go towards wasted food (Kummu et al., 2012). In the United States, over one quarter of freshwater use and $4 \%$ of oil use is accounted for by wasted food (Hall et al., 2009). Economically, the total value of food lost at the retail and consumer levels in the United States is $\sim \$ 161.6$ billion annually, which translates to $\$ 371$ worth of food wasted per capita at the consumer level or $9.2 \%$ of each consumer's average annual food spending (Buzby et al., 2014). With regards to diets and health, the amount of food wasted at the retail and consumer levels in the United States totals 1,249 calories per capita per day (Buzby et al., 2014). The caloric loss of food wasted at the consumer and retail levels represents a threat to food security with $10.5 \%$ of households in the United States experiencing food-insecurity annually (USDA ERS, 2019). Globally, over 690 million people are chronically undernourished, an estimate which does not account for the COVID-19 pandemic (FAO, 2020). Compounded with a growing global population, there is a projected need for a $50-70 \%$ increase in the worldwide food supply by 2050 (Food and Agriculture Organization, 2009; Alexandratos and Bruinsma, 2012; Bond et al., 2013). Climate change, land availability, water scarcity, and other environmental and societal factors present major constraints to being able to sustainably increase food production by $50-70 \%$ (Wheeler and von Braun, 2013; Willett et al., 2019). Overall, society cannot afford to lose food in the food system as waste so that is can better support human wellbeing and planetary health.

Given the critical need to decrease food waste to more sustainably feed the world's population, countries and organizations around the world have set goals for reducing food waste. For example the Sustainable Development Goal 12 of the United Nations promotes Responsible Consumption and Production (United Nations, 2015). In the United States, the US Department of Agriculture and Environmental Protection Agency partnered to create food waste reduction goals to reduce per capita food waste by $50 \%$ by 2030 (United Nations, 2015; USDA, 2015). Given the notable role that consumers play a notable role in generating food waste in high-income countries such as the United States, evidence-based education, programs, and policies are called for to reduce food waste that are locally relevant.

Previous studies highlight the need to understand food waste within the routines and resources of households towards developing evidence-based education campaigns, interventions, and policies (Evans, 2011; Quested et al., 2013; Graham-Rowe et al., 2014; Porat et al., 2018; Willett et al., 2019; Turvey et al., 2021). Effective evidence-based consumer food waste reduction strategies have been implemented in several European countries (Parry et al., 2014; Schmidt, 2016). Previous research on consumer knowledge and behaviors in the United States with regards to food waste found that three quarters of respondents reported to waste less food than is estimated for the average American, highlighting that consumers are either not aware of how much food they waste or the actual scale of food waste nationally (Neff et al., 2015). Top motivations for reducing food waste among consumers in the United States include saving money and setting a good example for children, while environmental reasons were ranked last (Neff et al., 2015). Another national study in the United States found that consumers' decisions to waste food vary based on demographic and contextual factors including the price of food, amount of food, smell of food, availability of a replacement, and if the food is a leftover meal versus a single ingredient (Ellison and Lusk, 2018).

However, while trends regarding consumer food waste have been reported at the national scale, there remain gaps in understanding consumer food waste dynamics at local levels in order to design evidence-based solutions that are place-based and context specific. Research is further needed to examine trends in consumer perception, behaviors, and knowledge since the implementation of national targets to reduce food waste in 2015. This study examines consumer perceptions, behaviors, and knowledge of food waste at the household level in Montana, a rural agricultural state in the United States, through an online survey that was distributed through community groups. Findings are expected to inform the development of evidence-based solutions that are place-based and locally relevant.

\section{Study Location}

A structured survey was administered in the rural agricultural state of Montana in the United States in 2016. Montana was selected as a study site as it is where the research team is based. The state has a population of 1,084,225 (US Census Bureau, 2020). Several distinct features of Montana compared to other states in the United States include: (1) being the third leastdensely populated state in the United States; (2) having an agricultural economy based on ranching and cereal farming; (3) being the home of seven Native American reservations and the ancestral homelands of multiple tribes of indigenous people; (4) being a red state with a track record of the majority voting Republican since 1968; (5) having a large majority Caucasian population and; (6) having a rapidly-growing tourism sector for its multiple national parks and mountain ranges as part of the Rocky Mountains. In addition to being one of the least densely populated states, $76 \%$ of US states (territories not included) have at least one county with a population greater than the entire state of Montana based on the 2013 Rural-Urban Continuum Codes (RUCC), a USDA ERS classification system of counties in the United States by population (Supplementary Figure 1). The Rural-Urban Continuum Codes include RUCC codes 1 through 9, with RUCC code 1 including the most populous metropolitan counties with over one million people, and a RUCC code of 9 that includes the least populous and nonmetropolitan and rural counties with under 2,500 people (USDA Economic Research Service, 2013).

\section{Survey Development and Administration}

Our study team developed a survey based on previous consumer surveys on food waste including national studies in the United States (Parry et al., 2014; Neff et al., 2015; Qi and Roe, 2016) coupled with additional questions in order to address the overall research question: What are consumer attitudes, behaviors, knowledge, and perceptions about food waste and what factors contribute to household food waste and food 
waste reduction in Montana? Additionally, the survey was designed to address the following specific research questions: (1) What are consumer food procurement practices, behaviors, and perspectives in Montana?; (2) What is consumer behavior regarding food date labels, food storage, dietary planning, consuming leftovers, cooking, composting, and food waste in Montana?; (3) How do consumers perceive various strategies to reduce food waste in terms of ease and efficiency as part of their daily schedules in Montana?; (4) How do consumer practices, behaviors, and perspectives regarding food waste vary based on demographics?

The survey was field tested among a group of consumers and experts in the fields of behavior science, sustainable food systems, and nutrition and refined based on feedback. The final survey had a total of 35 questions and was administered online using the Qualtrics survey platform through the HELPS LAB at Montana State University. The research team contacted Extension services, community organizations (examples: farmer associations, food bank network, community colleges), and community list serves across the state of Montana to distribute the survey using purposive sampling. The survey was distributed to over 3,000 adults with a completion rate of over $10 \%$. Permission for the participation of human subjects in the survey was granted by the Institutional Review Board at Montana State University. The first 100 participants to complete the survey received a \$15 gift card for participating in the study as a study incentive.

\section{Data Analysis}

For each survey question, responses were tabulated based on frequency of response options for the number of participants that answered the question. Given that some participants refrained from answering some questions, sample size may vary among survey questions. Statistical analysis was conducted using JMP SPSS software. A contingency analysis was completed for select survey questions to understand differences in responses based on demographic characteristics with the Pearson $p$-value reported at a significance level $p<0.05$. Demographic characteristics were categorized by generation (age), income (perceived ability to meet basic needs of the household), rurality, and level of involvement in household food management. Specifically, responses were analyzed for differences among generational age groupings based on age during the survey distribution year 2016 and included the following groups: (1) "Millennial+" comprised of Generation $\mathrm{Z}$ ages 19 years and under, and Millennials ages 20-35 years; (2) "Generation X" comprised of Generation X ages 36-51 years; and (3) "Baby Boomer+" comprised of the Baby Boomer generation ages 52-70 years and the Post War generation ages 71 years and older. Differences in income were also analyzed using a proxy for income level and included households having (1) "less than enough," (2) "enough," and (3) "more than enough" to meet household needs. The rurality of informants was assigned by Rural-Urban Continuum Codes (RUCC). Since Montana is largely rural, RUCC's were further combined and included nonmetropolitan counties (1) RUCC 8-9 completely rural or $<2,500$ urban population, both adjacent/not adjacent to a metro area, (2) RUCC 6-7 urban population of 2,500-19,999 both adjacent/not adjacent to a metro area, (3) RUCC 5 urban population of 20,000 or more, adjacent/not adjacent to a metro area (there are no RUCC 4 codes in MT), and finally metropolitan counties, (4) RUCC 3 (there are no RUCC codes 1-2). In addition, responses were analyzed for differences based on active role in managing the kitchen, grocery/food shopping, and cooking and included (1) "I manage most," or (2) "I manage half." The response option "I do not [manage/shop/cook]" was not included in the analysis due to low frequency of response selection and resulting small sample size. The response options that included a 6point Likert scale were re-grouped for the statistical analysis and included the following groupings: "Often/Always," "Sometimes," and "Rarely/Never." The response option "Not applicable" was not included in the statistical analysis.

\section{RESULTS}

\section{Consumer Background}

A total of 329 adult participants completed the majority of the food waste survey between the ages of 19-75, with a mean age of 41 years. Economically, most participants shared they felt financially comfortable regarding access to food; a majority (63\%) of participants indicated they have "plenty of food and lots or some to share" while around a quarter (26\%) indicated that "have enough," $10 \%$ indicated they "have enough but stretch resources," and $1 \%$ indicated they need support meeting their basic food needs.

Most participants reported they live in a non-metropolitan county with an urban population of 20,000 or more (46\%), followed by those living in a metropolitan county in metro areas of fewer than 250,000 (28\%), non-metropolitan county with an urban population of 2,500-19,999 (16\%), and non-metropolitan county completely rural or $<2,500$ urban population $(10 \%)$. By contrast, just over half of all Montana counties have RUCC codes 8-9 (54\%), followed by RUCC code 6-7 (32\%), and RUCC codes 5 and RUCC code 3 (7\%) (Supplementary Figure 1) (USDA Economic Research Service, 2013).

The majority of participants (69\%) reported they do all or most of the food shopping in the household, $28 \%$ do approximately half the food shopping, and 3\% indicated that someone else in their household does all or most of the food shopping. Almost three fourths (74\%) of participants indicated they do all or most of the organizing and managing of food items in the kitchen, near one quarter $(23 \%)$ stated they do about half of the organization and management, and 3.3\% stated this is someone else's role in their household.

Regarding food preparation, over half (63\%) of participants reported they do all or most of the cooking in the household, near one third (29\%) stated they do half, and $8 \%$ stated that someone else does all or most of the cooking. Almost three fourths of participants $(72 \%)$ indicated that they cook meals daily, while near a quarter (24\%) reported they cook a few times a week, and a small percentage (4\%) cook meals at home once a week. Regarding consumption of meals outside of the home, over one third $(36 \%)$ of participants stated they eat outside of the home a few times a week, approximately one quarter (24\%) eat outside once a week, another near quarter (26\%) eat outside of the home 
less than once a week, and 13\% stated they eat outside of the home on a daily basis.

\section{Consumer Food Procurement Perceptions and Behaviors}

Multiple food shopping behaviors were reported that can facilitate reducing household food waste including (Figure 1): (1) making a shopping list before going to the grocery store (65\% of participants); (2) always or often checking to see what is in the refrigerator and pantry before going to the grocery store (65\%); (3) always or often planning meals before grocery shopping (50\%); (4) always or often estimating how much of various items will be needed before shopping (64\%); (5) always or often sticking to their grocery shopping list at the store $(65 \%)$; (6) rarely or never getting tempted in the store to buy appealing products that may not be eaten (52\%); (7) rarely or never buying larger packages of food that are likely to go to waste $(47 \%)$ and; (8) rarely or never buying more food than needed due to items being on sale (59\%). Concurrently, a majority $(61 \%)$ of informants reported they sometimes go to the grocery shop on an empty stomach. Significant differences in shopping behaviors were found among the three generational groupings, and between participants with an active role in kitchen management, shopping, and cooking $(p<0.05)$. Specifically, the proportion of those that planned ahead for shopping based on estimating their need and were rarely tempted by in store appeal and rarely bought in larger bulk packaging, due to sales, and rarely shopped on empty stomachs were higher for the Baby Boomer+ group than the other generations. Differences were not significant by perceived household income level and rurality. Those that do most to all kitchen management, shopping, or cooking more prevalently reported they often/always check fridge before shopping, estimate items needed before shopping, stick to a shopping list while in the store, and rarely/never tempted by in store buying appeal, buy larger packages of food that what they will use, and buy more food due to sales. Those that manage the kitchen, shopping, or cooking half the time more prevalently shop on an empty stomach.

The majority of participants either strongly disagreed (34\%) or disagreed $(26 \%)$ to the statement "I buy more processed foods than I would otherwise because fresh foods spoil more quickly." A quarter of participants either agreed (19\%) or strongly agreed $(6 \%)$ to this statement regarding processed foods while $14 \%$ neither agreed nor disagreed. Similarly, the majority of participants either strongly disagreed $(28 \%)$ or disagreed $(25 \%)$ to the statement "I buy more canned foods than I would otherwise because fresh foods spoil more quickly." Just over a quarter of participants either agreed (22\%) or strongly agreed (5\%) to this statement regarding canned foods while $20 \%$ neither agreed nor disagreed.

The majority of participants either strongly disagreed (37\%) or disagreed (32\%) to the statement "fresh foods go bad/get spoilt because people in the household prefer other foods." Less than a fifth of participants either agreed (13\%) or strongly agreed (5\%) to this statement regarding fresh foods while $12 \%$ neither agreed nor disagreed. The majority of participants either agreed (37\%) or strongly agreed (19\%) that they purchase more fruits and vegetables than they would otherwise due to nutritional content. Nearly a quarter neither agreed nor disagreed $(24 \%)$ while nearly a fifth of participants either disagreed (13\%) or strongly disagreed (6\%) with this statement regarding the nutrient content of fruits and vegetables.

\section{Consumer Food Waste Perceptions, Behaviors, and Knowledge}

Participants reported variably wasting different types of food (Figure 2) with the least wasted food item being packaged foods (60\%) followed by milk and meat. Nearly all participants (95\%) reported they waste food in the household, with variation in the amount wasted. Just over half (53\%) of the participants reported they waste about $10 \%$ of food purchased, near a quarter (26\%) reported to waste about $20 \%$ of food, and near a tenth (12\%) reported wasting $30 \%$ of food. A small percentage of participants (2\%) reported wasting $\sim 40 \%$ of food and $<1 \%(1 \%)$ reported wasting $50 \%$ or more of the food they procure. Approximately half $(52 \%)$ of the participants reported that they rarely or never throw away leftovers while $43 \%$ claimed they sometimes throw away leftovers. Only $6 \%$ of participants reported they often throw out leftovers. Nearly three-quarters $(73 \%)$ of participants reported they rarely or never throw away food due to not liking the taste and nearly a quarter of participants (24\%) reported they sometimes throw out food due to not liking the taste. Only $3 \%$ of participants reported they often throw out food because of disliking the taste. Just over half (52\%) reported they sometimes forget about items in the fridge until they are too old to eat, one-third (34\%) of respondents reported they rarely or never forget, and $14 \%$ reported they often do. When food is wasted in the household, participants dispose of food in multiple ways including discarding of food in the trash (69\% of participants), composting (47\%), using the garbage disposal, and feeding excess food to pets/livestock (26\%).

When deciding whether or not to discard food, almost all (92\%) of participants reported that they make decisions either based on "use-by," "sell-by," or "best before" date labels. Just over a third (33\%) of participants make decisions depending on the food type, near a third (28\%) refer to labels most of the time, less than a fifth (17\%) sometimes make decisions based on food date labels and $14 \%$ of participants reported they always make decisions based on food date labels. Nearly three fourths (74\%) of participants indicated that they use their senses (smell, taste, and sight) when deciding whether to throw out milk, $29 \%$ look at the "use by date," $17 \%$ look at the "sell by date," and the remaining participants think about how long the milk has been in the household or whether it was left out of the refrigerator.

Knowledge regarding the amount of food wasted in the United States varied among participants with almost one-third of participants thinking that $\sim 40 \%$ of food is wasted nationally (29\%), about one-quarter thinking $30 \%$ is wasted (26\%), onefifth thinking $20 \%$ is wasted (19\%), while a smaller minority reported thinking $50 \%$ or more of food is wasted (17\%), and 


\section{Food Shopping Behaviors}

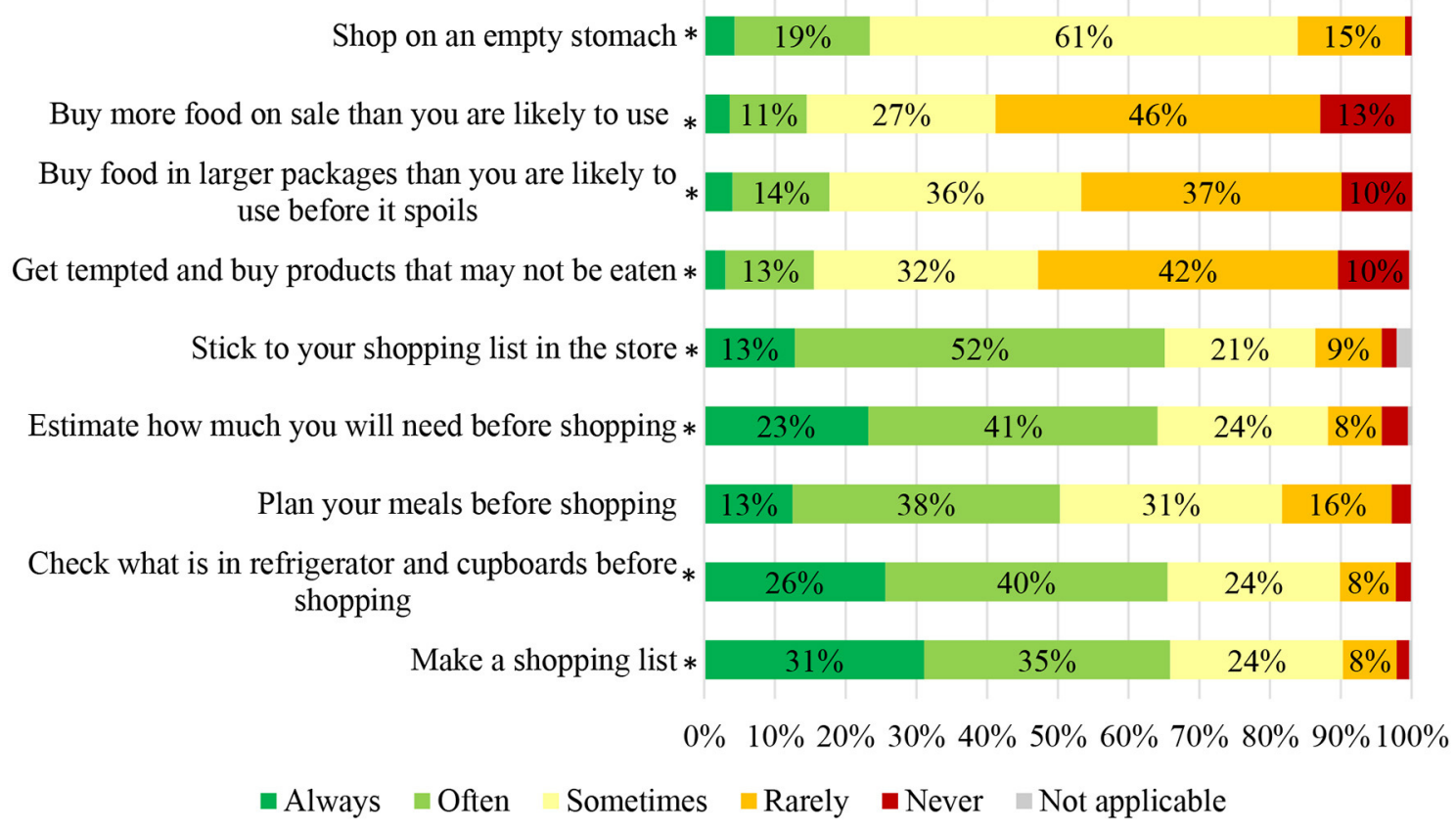

FIGURE 1 | Self-reporting of grocery shopping practices and behaviors (values $<5 \%$ not labeled in figure; * ${ }^{*}$ ignificant differences $p<0.05$ ).

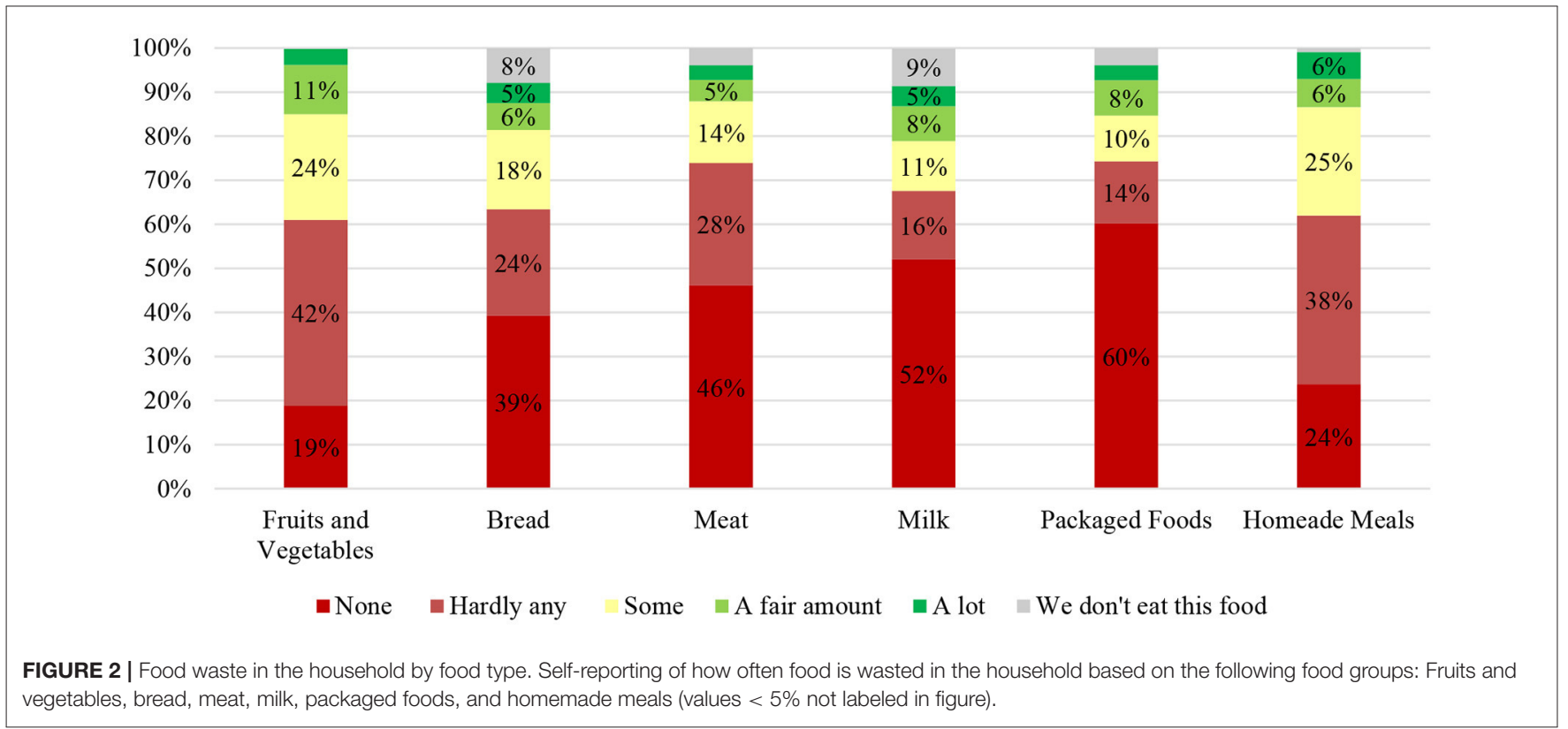

even less thinking that $10 \%$ of food is wasted (9\%). Differences were significant among the generational groups $(p<0.05)$. Overall, participants that perceived food waste to be under $20 \%$ were more prevalent among the Millennial+ group (34\%), followed by Generation X (30\%), and less prevalent in the Baby Boomer+ group (16\%). The majority $(63 \%)$ of respondents reported hearing or learning about the issue of food waste in the past year via news, social media, or elsewhere, near one third (28\%) had not recently heard about the issue of food waste, and $8.8 \%$ were unsure. The majority of participants (71\%) perceived their household food waste to be less than the average American, 20\% perceived they produced the same amount of 
waste as the average American, 6\% perceived they produced more waste than the average American, and 3\% were unsure. Differences were significant among the generational groups and those with an active role in kitchen management $(p<0.05)$. Of the generational groups, none of the participants in the Baby Boomer+ group perceived they waste "more," with 95\% reporting they waste "less" than the national average. Similarly, none of the participants that managed the kitchen half the time perceived they waste more than average, with $85 \%$ reporting they waste less. Differences were not significant by perceived household income level and rurality. The majority (66\%) of participants reported that discarding food "bothers them a lot," near a third (29\%) reported that household food waste "bothers them a little," and a small percentage reported that discarding food does not bother them at all $(6 \%)$ or were unsure $(6 \%)$.

Half (50\%) of participants agreed with the statement that they throw away food because they are worried about food poisoning and $39 \%$ of participants disagreed with this statement. Nearly half (47\%) of the participants disagreed that food waste costs them money while just over half (34\%) agreed that food waste costs them money (Figure 3).

\section{Consumer Perceptions and Behaviors to Reduce Food Waste}

The majority of participants (61\%) reported that they did not seek out information about strategies to reduce household food waste while the remaining participants (39\%) did. There were significant differences among generational groups $(p<$ 0.05 ) with the greatest prevalence of Millennials that reported to seek information on reducing housed food waste (51\%). Differences were not significant by food management roles, rurality, or household income level. The majority of participants perceived they were either fairly knowledgeable (44\%) or very knowledgeable $22 \%$ about strategies to reduce food waste and $25.4 \%$ felt they were somewhat knowledgeable about food waste reduction strategies. Most participants perceived that they made either a moderate amount of effort (49\%) or a lot of effort (29\%) to reduce food waste. A fifth of the participants (20\%) reported that they made little effort and a small percentage (3\%) reported they made no effort to reduce household food waste. There were significant differences among those who have an active role in cooking $(p<0.05)$ with the greatest prevalence of participants that reported they currently make "a lot" of effort to reduce food waste coming from those that reported they cook "most of the time" (79\%). Participants reported engaging in multiple food waste reduction strategies with regards to food storage and preparation (Figure 4) with prevalent practices being to make sure to cook food before it goes bad $(67 \%)$ and to prioritize to eat leftover foods or foods close to expiration $(60 \%)$.

The majority of participants reported they were either very interested (48\%) or fairly interested (36\%) in taking additional action to reduce their household food waste, $13 \%$ reported they were somewhat interested, and $4 \%$ were not at all interested. Of those respondents that reported they had some level of interest in taking action to reduce waste, there was a significant difference between those that have an active role in cooking and rurality $(p<0.05)$. Specifically, participants that do "most to all" of the cooking more prevalently reported they were very interested in reducing household food waste as well as participants that live in urban populations of 20,000 or more. Participants expressed interest in learning additional strategies to reduce household food waste including: (1) what can be frozen and for how long (52\%); (2) recipes to help use up food (44\%); (3) how to creatively use leftovers (42\%); (4) what foods are dangerous when spoiled versus simply distasteful (41\%); (5) how to store specific items (35\%); (6) how to interpret food date labels (29\%); and (7) apps or online programs to help with food shopping and portion planning (14\%). Approximately a third of participants (37\%) perceived it would be easy to notably reduce their household food waste, $28 \%$ perceived it would be neither difficult nor easy, $18 \%$ perceived it would be difficult, $14 \%$ perceived it would be very easy, and $4 \%$ perceived it would be very difficult.

The majority of participants generally agreed regarding factors that they perceived as either very important or important in motivating them to reduce household food waste (Figure 5) including wanting to set a good example for their children, personal guilt, and the possibility of saving money.

\section{Consumer Perceptions on Strategies to Reduce Food Waste in Market and Food Service Food Environments}

With regards to market food environments such as grocery stores and supermarkets, the majority (62\%) of survey respondents agreed that they find desirable strategies that offer discounts on over-ripe produce or food near its expiration date. Other strategies that the majority of respondents perceive as acceptable for market food environments are: (1) access to "bulk food" bins where customers can scoop out exactly how much food they need (59\%); (2) "buy one, get one later" offers rather than "buy one, get one" (55\%); and (3) discounts on produce that is less visually appealing (51\%). A notable amount of respondents also found desirable the strategies of having more foods offered in resealable packages $(48 \%)$ as well as a greater availability of a variety of food product sizes and/or packaging options (46\%).

With regards to food service food environments such as restaurants, strategies that the majority of respondents perceive as acceptable are: (1) donating excess food (70\%); (2) offering smaller portion sizes with an option for "free refills" (65\%); and (3) providing smaller plates at the salad bar for buffetstyle restaurants (55\%). A notable amount of respondents also found desirable the strategy of waiting longer for items "made to order" rather than purchasing ready-made items (45\%). A third of respondents (32\%) perceived offering less variety on a menu as acceptable and another third perceived not providing trays at the salad bar (31\%) as acceptable.

\section{DISCUSSION}

This study highlights that food waste is a concern among consumers in the rural American state of Montana and that 
Other people in my household don't like when I try to use up older food

Given the amount of food that is thrown out in this country, my individual actions would not make much...

Food is natural and breaks down in the landfill, so throiwing it out does not bother me

I sometimes throw out food because I worry about food poisoning

I want to eat only the freshest foods, so throwing out less fresh food does not bother me that much

My household's uneaten food is composted, so throwing it out does not bother me

I don't think the amount of food I throw away costs me much money

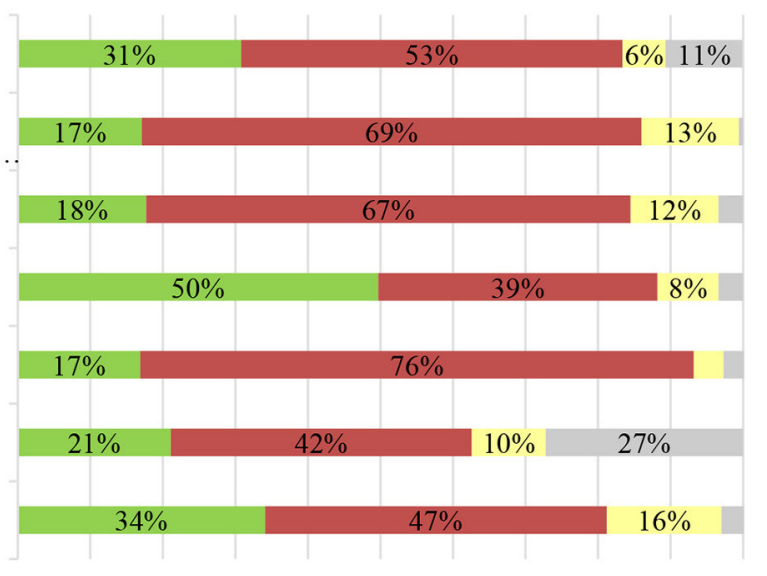

$\begin{array}{lllllllllll}0 \% & 10 \% & 20 \% & 30 \% & 40 \% & 50 \% & 60 \% & 70 \% & 80 \% & 90 \% & 100 \%\end{array}$

$\square$ Agree $\quad$ Disagree Don't know $\square$ Not applicable

FIGURE 3 | Consumer perceptions of household food waste production. Consumer agreement pr disagreement regarding their perceptions of household food waste (values $<5 \%$ not labeled in figure).

Make sure to cook food before it goes bad

Make sure not to make too much food

Eat at home if you have food to use up, even if you feel like going out

Prioritize eating leftover and foods close to expiration or spoilage

Use leftovers or food scraps as ingredients in future meals

Freeze food if you think you will not be able to eat it in time

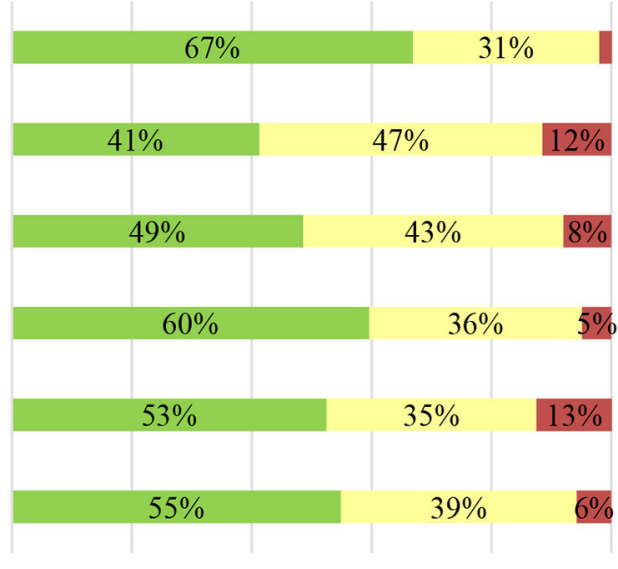

- Often Sometimes $\quad$ Rarely or never

FIGURE 4 | Participant engagement in household food waste reduction strategies. Participants were asked to report how often they engage in six household food waste reduction strategies/practices (values $<5 \%$ not labeled in figure).

place-based solutions are needed to further reduce food waste. There was a higher prevalence of significant differences in shopping behaviors among the Baby Boomer+ generation and those with an active role in kitchen management, cooking, or shopping. This points to those having greater experience (experience with age and/or kitchen roles) tend to have more prevalent shopping behaviors that may lead to waste reduction. Differences were not significantly different based on rurality and perceived household income. Variation regarding consumer food waste dynamics such as motivators for reducing food waste were found in our Montana-based study compared to previous national studies, calling for solutions that are place-based and locally relevant. The majority of participants: (1) have heard about food waste issues in the past year; (2) are implementing multiple strategies to reduce food waste; (3) are willing to learn about additional strategies to reduce food waste and; (4) perceive it would be relatively easy to reduce their household food waste. The most commonly reported reasons for wasting food were for forgetting about food and disposing it due to safety concerns. However, while participants noted they are willing to reduce food waste, the majority reported that they did not seek out information about strategies to reduce household food waste. 
Wanting to set an example for my children and/or others

Thinking about the idea that I can make a difference for a better world through my actions

Thinking about the greenhouse gases, energy and water resources it took to get the food to my plate

Feeling guilty about waste in general

Wanting to manage my home efficiently

Feeling regret about time spent shopping, storing, or preparing food not eaten

Thinking about the possibility of saving money

Thiking about people without enough to eat

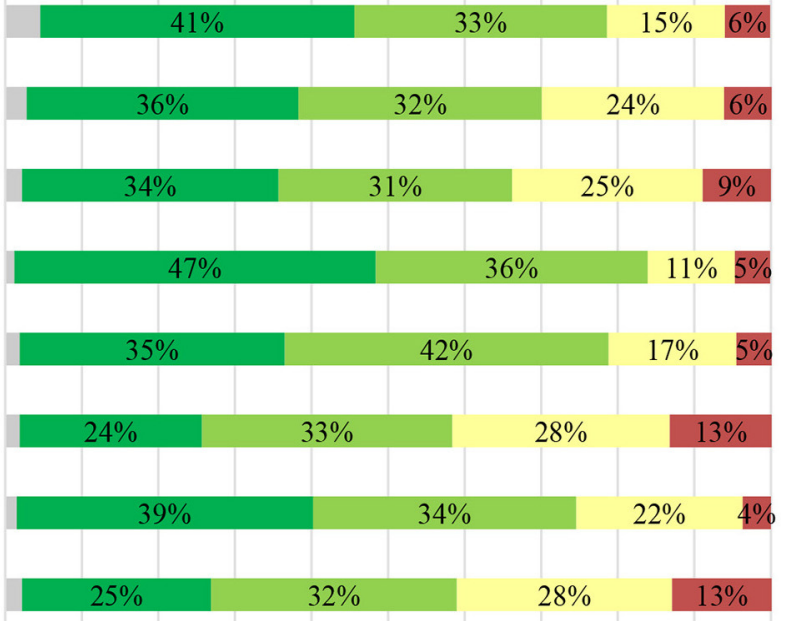

Somewhat important $\quad$ Not at all important

FIGURE 5 | Motivating factors for reducing food waste. Participants were asked to report how important the following factors are in motivating them to reduce food waste (values $<5 \%$ not labeled in figure).

Thus, food waste campaigns should be administered through local community organizations and enterprises to provide households with strategies to reduce food waste including tips with meal planning and safe food storage. In addition, future work should enhance consumer knowledge regarding the extent of food waste through participatory approaches such as citizen-science. As place-based solutions should draw upon local factors, this study indicates that programming in Montana should take into consideration social factors of guilt and setting a good example which were found to be key motivators for reducing food waste. Concurrently, programming should provide education on the tremendous impacts of food waste on the environment as well as economically for supporting food security in order to advance consumer knowledge in these areas for enhancing equitable and sustainable food systems.

Both commonalities as well as differences were found in survey responses from our Montana-based study compared to two previous national-level surveys, emphasizing the importance of place-based understanding for informing evidence-based programs and policies. Findings of this study regarding the amount of food waste reported by the majority of participants ( $10 \%$ or less of food) is comparable to consumer reporting of a national study (Neff et al., 2015) and is notably lower compared to the national average of food waste estimates between $30-$ $40 \%$ (Buzby et al., 2014). This study further found that $71 \%$ of participants perceived their household food waste to be less than the average American while previous findings by the national survey by Neff et al. (2015) found that almost all (97\%) of participants reported wasting less than the average American. As our study along with that of Neff et al. (2015) involved selfreporting of food waste, consumers are likely not aware of the extent of their food waste and/or may intentionally underreport their food waste. Previous studies suggest that consumer's generally underestimate the amount of their household food waste and that this limitation can be overcome through waste audits, participant journaling, and ethnographic studies (Quested et al., 2013). However, perceptions regarding the amount of food wasted by consumers of our Montana-based study are more aligned to national averages of food waste quantities compared to perceptions previously reported in the national study by Neff et al. (2015). This greater alignment of food waste knowledge by study participants may potentially be due to an increased understanding of food waste due to media and programming since the implementation of national targets in 2015 to reduce food waste. A greater proportion of participants (63\%) from our Montana-based study reported that they have heard about food waste in the past year through the news, social media, or other means compared to the percentage of participants (42\%) in a national study by Neff et al. (2015). Overall, participants of our Montana-based study were more willing to take additional action to reduce their household food waste ( $48 \%$ of participants) than the national survey (23\% of participants in Neff et al.'s study; 2015) while the percentage of participants who perceive it will not be difficult to notably reduce their food waste is similar to national survey [ $84 \%$ of consumers (Neff et al., 2015)].

Guilt emerged as a major determinant for reducing food waste by almost half the participants of our Montana-based study compared to one third in the previous national study by Neff et al. (2015). Understanding the role of personal guilt as a determinant of reducing food waste is thus important for designing education and programming for reducing consumer food waste. Previous studies have found that religious affiliation 
is significantly related to guilt (Albertsen et al., 2006). While our survey did not ask people about their religious affiliation, $\sim 65 \%$ of the adult population in Montana professes Christianity, which is aligned to the national average (Albertsen et al., 2006). Given the association of guilt with religious affiliation, local food waste programming may consider engaging faith communities. Multiple programs have previously enlisted faith communities to fight food waste (NPR, 2016). For example, the United States Environmental Protection Agency launched the Food Steward's Pledge to engage religious groups of all faiths to help redirect food waste to hungry mouths as part of targets to reduce food waste by 2050 (EPA, 2016). Local community leaders have been recognized to be critical in getting out the message of what individual families can do to reduce food waste (EPA, 2016).

While guilt and setting a good example were found to be greater motivators for reducing food waste compared to economic and environmental factors, a greater number of participants compared to the national study by Neff et al. (2015) are motivated to reduce food waste on the basis of environmental factors (including the greenhouse gasses, energy, water, and resources used to get food to their plate) while being in line with the national survey by Qi and Roe (2016). Previous survey research has found that consumers in Montana are more willing than consumers in some other parts of the country to pay price premiums on food and beverage items for supporting environmental sustainability (Boehm et al., 2019), suggesting a potential difference in environmental values of residents of Montana compared to other states. Being a rural state prized for its wilderness, healthy ecosystems (including the Greater Yellowstone Ecosystem), and biodiversity, some residents in Montana may have a land ethic that enhances their valuation of environmental resources. However, given that social factors were greater motivators than environmental and economic factors for reducing food waste, education is needed regarding the impacts of food waste on the environment as well as economically for supporting food security. While household food security is near the national average in Montana, rural areas in Montana have lower food security (USDA ERS, 2019); it is thus important for households in these areas to understand how reducing food waste can support food security.

Given that the majority of participants are very interested in reducing their household food waste and perceive it would not be difficult to reduce their food waste, findings indicate the potential to reduce consumer food waste in Montana through research, education, interventions, and policy. Promising strategies to include in place-based community education and other initiatives to reduce food waste based on this study and the literature include:

(1) Develop skills on safe storage practices including how to refrigerate, freeze, dry, ferment, pickle, and cook foods as well as literacy on duration for each storage technique.

(2) Enhance literacy on food safety regarding food labels ("best by" vs. "use by" dates) and what foods are dangerous when spoiled versus being distasteful.
(3) Develop creative, delicious, and culturally-relevant recipes that incorporate food that would be wasted such as repurposing leftovers, using fruit to create shrubs and other drinks, and using vegetables to create sauces and soups.

(4) Promote skills and behavior associated with meal planning to budget food usage throughout the week such as avoiding grocery shopping when hungry to avoid impulse buying and making shopping lists for the meals to be eaten in a week.

(5) Organize food storage spaces so that older and more perishable items are visible.

(6) Foster mindful eating during meals by reducing the size of plates and bowls, reducing portion sizes, eating slowly, and paying attention to what is being consumed and wasted.

(7) Support composting of produce at the household level through community-organized initiatives involving accessible anaerobic digestors that divert produce that can't avoid being wasted from the landfill.

(8) Donate nutritious, safe, and untouched food to food banks/nutrition assistance programs when it cannot be consumed at the household-level.

Community groups such as Extension, nonprofit organizations, faith groups, social influences, popular media, and food enterprises can serve as leaders to engage consumers in community education regarding food waste including enhancing knowledge while targeting context-specific behaviors and motivating people to feel responsible for reducing food waste. In addition to household food waste, the surveyed consumers supported various strategies to reduce food waste in their food environments (markets and food service) including: (1) discounts on over-ripe produce or food near its expiration date; (2) bulk food bins where customers can scoop out exactly how much food they need; (3) providing "buy one get one later" offers rather than "buy one get one" offers; (4) offering discounts on produce that is less visually appealing; (5) donating excess food; (6) providing smaller portions in restaurants with the option for "free refills,; and (7) providing smaller plates at salad bars.

Findings from this study have the potential of informing existing organizations initiatives in their food waste efforts. Multiple businesses, organizations, and community groups are becoming more proactive about food waste community education and reduction strategies in Montana (Supplementary Table 1). At consumer levels, organizations such as Zero by Fifty Missoula encourage households to reduce food waste and promote compost collection organizations. These compost collection companies are located throughout the state and create residential and commercial compost opportunities. Several research projects in MT are also engaging local households regarding food waste and composting. For example, Montana State University is taking a citizen-science approach partnering with the city of Bozeman and local households to study household food waste and explore the potential to use anaerobic digestion for processing household food waste in the city, applying a decentralized and household approach to organic waste management. Schools have been implementing programs such as Smarter Lunchrooms to increase awareness about lunchroom food waste. At the two largest universities in 
the state, Montana State University and University of Montana, food waste reduction efforts are implemented in the dining halls using software to ensure appropriate ordering, composting, and marketing directed towards students. Organizations such as Helena Food Share, Montana Food Bank Network, and Missoula Food Bank and Community Center are utilizing food recovery programs by partnering with local grocery stores and businesses to rescue food and stock food banks with food that would otherwise be set aside for the landfill.

In addition to local efforts, national and international efforts should be modified with place-based adaptations. Organizations such as the Environmental Protection Agency and the United States Department of Agriculture are already working in this capacity with their efforts to work with communities, organizations, and businesses along with state, tribal and local governments to reduce food loss and waste by $50 \%$ by 2031 . Findings from this study and other local studies can inform these existing initiatives to enhance their local relevance.

Lastly, technological developments should be leveraged to better inform households regarding when food is unsafe to eat and needs to be disposed or composted. In recent years, chemical and biological sensors are being developed for food quality monitoring including sensors for measuring biomarkers of freshness, allergens, pathogens, adulterants and toxicants (Mustafa and Andreescu, 2018). These sensors are based on various technologies including colorimetric, electrochemical, optical, and mass-based detection and ultimately provide an "index of quality" of the product in real time (Mustafa and Andreescu, 2018). Deployment of such food quality monitors in ways that are affordable and accessible for consumers as well as stakeholders throughout the supply chain could lead to notable transformation of the food system with respect to food waste reduction. Advances in packaging, such as smart packaging, with built in sensors to detect bacterial growth would further help prevent food waste of packaged foods at the household level as well the entire supply chain from farm to plate (Mustafa and Andreescu, 2018).

Overall, on the basis of the evidence from our Montana-based household study and the food waste literature, we propose the following community education and research recommendations for reducing consumer food waste towards enhancing the sustainability of food systems for supporting planetary health:

(1) Evidence-based interventions, programs, and policies to reduce food waste should be place-based in order to be locally relevant by acknowledging context-specific social, environmental, economic, and health factors that influence value-systems, perceptions, knowledge, and behaviors such as factors that motivate consumers to reduce food waste as well as gaps in their understanding.

(2) Community groups such as faith groups, food enterprises, social influences, popular media, Extension, and nonprofit organizations should be recognized as potential leaders to engage consumers in community education regarding reducing food waste for achieving multiple sustainability in ways that are locally relevant.
(3) Given that consumer's generally underestimate the amount of household food waste, research is called for to acquire accurate data regarding food waste quantities through community-based participatory approaches. For example, a citizen-science approach for monitoring food waste through food waste audits and participant journaling has the potential to enhance consumer food waste literacy while providing quantitative evidence regarding how households across geographic areas respond to food waste programming. Citizen science has been recognized to be a practical way to produce large longitudinal data sets (Dickinson et al., 2010). Such a citizen science approach would require the management of big data through a large database that could continue to inform research priorities, food waste reduction targets, and other associated sustainability goals.

(4) Development and deployment of accessible, sensitive, and reliable hand-held food quality monitors for household use to determine food safety and produce freshness in order to better inform consumers regarding when food becomes unsafe to eat. The development of such technology requires cross-sector and interdisciplinary collaboration to develop biological and chemical sensors that can detect biomarkers of food freshness as well as pathogens (Mustafa and Andreescu, 2018).

\section{DATA AVAILABILITY STATEMENT}

The raw data supporting the conclusions of this article will be made available by the authors, without undue reservation.

\section{ETHICS STATEMENT}

The studies involving human participants were reviewed and approved by Institutional Review Board at Montana State University. The patients/participants provided their written informed consent to participate in this study.

\section{AUTHOR CONTRIBUTIONS}

SA and CB designed the study with input from Montana State University HELPS Lab. All authors contributed to implementing the survey tool and data interpretation. TW led the statistical analysis and creation of graphs and Supplementary Material. SA, ES, and AS wrote the manuscript with input from all. All authors contributed to the article and approved the submitted version.

\section{FUNDING}

Research reported in this publication was supported by the National Institute of General Medical Sciences of the National Institutes of Health (under Award Numbers P20GM103474 and P20GM104417), Montana IDeA Network of Biomedical Research Excellence (MT INBRE), the Human Ecology Learning 
and Problem Solving (HELPS) Lab at Montana State University, the National Science Foundation (under Award Number NSF RII Track-2 FEC OIA 1632810).

\section{ACKNOWLEDGMENTS}

Authors extend gratitude to the following organizations for assisting with survey distribution: MSU Extension, Montana 4-H Center for Youth Development, MT Department of

\section{REFERENCES}

Albertsen, E. J., O’Connor, L. E., and Berry, J. W. (2006). Religion and interpersonal guilt: Variations across ethnicity and spirituality. Ment. Health Relig. Cult. 9, 67-84. doi: 10.1080/13694670500040484

Alexandratos, N., and Bruinsma, J. (2012). World Agriculture Towards 2030/2050: The 2012 Revision. Rome: FAO. Available online at: http://www.fao.org/3/ ap106e/ap106e.pdf (accessed June 15, 2021).

Boehm, R., Kitchel, H., Ahmed, S., Hall, A., Orians, C. M., et al. (2019). Is agricultural emissions mitigation on the menu for tea drinkers? Sustainability 11:4883. doi: $10.3390 /$ su11184883

Bond, M., Meacham, T., Bhunnoo, R., and Benton, T. G. (2013). Food waste within global food systems. UK: Global Food Security Programme. Available online at: http://cradall.org/sites/default/files/food-waste-report_0.pdf (accessed June 15, 2021).

Buzby, J. C., Farah-Wells, H., and Hyman, J. (2014). The estimated amount, value, and calories of postharvest food losses at the retail and consumer levels in the United States. U.S. Department of Agriculture, Economic Research Service. Available online at: http://www.ssrn.com/abstract=2501659 (accessed June 15, 2021).

Dickinson, J. L., Zuckerberg, B., and Bonter, D. N. (2010). Citizen science as an ecological research tool: challenges and benefits. Annu. Rev. Ecol. Evol. Syst. 41, 149-172. doi: 10.1146/annurev-ecolsys-102209-144636

Ellison, B., and Lusk, J. L. (2018). Examining household food waste decisions: a vignette approach. Appl. Econ. Perspect. Policy 40, 613-631. doi: 10.1093/aepp/ppx059

EPA (2016). EPA's Food Steward's Pledge. Available online at: https:// 19january2017snapshot.epa.gov/communityhealth/foodsteward_html (accessed June 6, 2021).

Evans, D. (2011). Blaming the consumer-once again: the social and material contexts of everyday food waste practices in some English households. Crit. Public Health 21, 429-440. doi: 10.1080/09581596.2011.608797

FAO, IFAD, UNICEF, WFP, and WHO. (2020). The State of Food Security and Nutrition in the World 2020: Transforming Food Systems for Affordable Healthy Diets. Rome, Italy: FAO, IFAD, UNICEF, WFP and WHO. doi: 10.4060/ca9692en Also Available in: Arabic Russian French Spanish Chinese.

Food and Agriculture Organization (2009). How to Feed the World in 2050. Rome, Italy: FAO. Available online at: http://www.fao.org/fileadmin/templates/wsfs/ docs/expert_paper/How_to_Feed_the_World_in_2050.pdf (accessed June 15, 2021).

Food and Agriculture Organization (2015). Global Initiative on Food Loss and Waste Reduction. Available online at: http://www.fao.org/3/i4068e/i4068e.pdf (accessed June 15, 2021).

Fox, T., and Fimeche, C. (2013). Global Food: Waste Not, Want Not. London, UK: Institute of Mechanical Engineers Available online at: https://www.ifama.org/ resources/files/2013-Symposium/TFox.pdf (accessed June 15, 2021).

Graham-Rowe, E., Jessop, D. C., and Sparks, P. (2014). Identifying motivations and barriers to minimising household food waste. Resourc. Conserv. Recycl. 84, 15-23. doi: 10.1016/j.resconrec.2013.12.005

Gunders, D., Bloom, J., Berkenkamp, J., Hoover, D., Spacht, A., and Mourad, M. (2017). Wasted: How America is Losing Up to 40 Percent of Its Food from Farm to Fork to Landfill. National Resource Defense Council
Agriculture, NCAP, AERO, MT Farmers Union, Montana Organic Association, One Montana, Bozone, MT Food Bank Network.

\section{SUPPLEMENTARY MATERIAL}

The Supplementary Material for this article can be found online at: https://www.frontiersin.org/articles/10.3389/fsufs. 2021.734785/full\#supplementary-material

Available online at: https://www.nrdc.org/resources/wasted-how-americalosing-40-percent-its-food-farm-fork-landfill (accessed June 15, 2021).

Hall, K. D., Guo, J., Dore, M., and Chow, C. C. (2009). The progressive increase of food waste in america and its environmental impact. PLoS ONE 4:7940. doi: 10.1371/journal.pone.0007940

Kummu, M., de Moel, H., Porkka, M., Siebert, S., Varis, O., and Ward, P. J. (2012). Lost food, wasted resources: global food supply chain losses and their impacts on freshwater, cropland, and fertiliser use. Sci. Total Environ. 438, 477-489. doi: 10.1016/j.scitotenv.2012.08.092

Mustafa, F., and Andreescu, S. (2018). Chemical and biological sensors for food-quality monitoring and smart packaging. Foods 7:168. doi: 10.3390/foods7100168

Neff, R. A., Spiker, M. L., and Truant, P. L. (2015). Wasted food: U.S. consumers' reported awareness, attitudes, and behaviors. PLOS ONE 10:27881. doi: 10.1371/journal.pone.0127881

NPR (2016). Thou Shalt Not Toss Food: Enlisting Religious Groups To Fight Waste. NPR.org. Available online at: https://www.npr.org/sections/thesalt/2016/01/ 18/463109192/thou-shalt-not- toss-food-enlisting-religious-groups-to-fightwaste (accessed June 6, 2021).

Parry, A., LeRoux, S., Quested, T., and Parfitt, J. (2014). UK food wastehistorical changes and how amounts might be influenced in the future. Waste and Resources Action Programme. Available online at: https:/wrap.org. $\mathrm{uk} /$ resources/guide/uk-food-waste-historical-changes-and-how-amountsmight-be-influenced-future (accessed June 15, 2021).

Porat, R., Lichter, A., Terry, L. A., Harker, R., and Buzby, J. (2018). Postharvest losses of fruit and vegetables during retail and in consumers' homes: quantifications, causes, and means of prevention. Postharv. Biol. Technol. 139, 135-149. doi: 10.1016/j.postharvbio.2017.11.019

Qi, D., and Roe, B. E. (2016). Household food waste: multivariate regression and principal components analyses of awareness and attitudes among U.S. consumers. PLOS ONE 11:e0159250. doi: 10.1371/journal.pone.0159250

Quested, T. E., Marsh, E., Stunell, D., and Parry, A. D. (2013). Spaghetti soup: The complex world of food waste behaviours. Resourc. Conserv. Recycl. 79, 43-51. doi: 10.1016/j.resconrec.2013.04.011

Schmidt, K. (2016). Explaining and promoting household food waste-prevention by an environmental psychological based intervention study. Resourc. Conserv. Recycl. 111, 53-66. doi: 10.1016/j.resconrec.2016.04.006

Turvey, C., Moran, M., Sacheck, J., Arashiro, A., Huang, Q., Heley, K., et al. (2021). Impact of messaging strategy on consumer understanding of food date labels. J. Nutr. Educ. Behav. 53, 389-400. doi: 10.1016/j.jneb.2021. 03.007

United Nations (2015). Transforming Our World: The 2030 Agenda For Sustainable Development. Available online at: https://sustainabledevelopment. un.org/content/documents/21252030\%20Agenda\%20for\%20Sustainable \%20Development\%20web.pdf (accessed June 15, 2021).

US Census Bureau (2020). U.S. Census Bureau QuickFacts: United States. Available online at: https://www.census.gov/quickfacts/fact/table/MT,US/POP010220 (accessed June 15, 2021).

USDA (2015). USDA and EPA Join with Private Sector, Charitable Organizations to Set Nation's First Food Waste Reduction Goals. USDS Office of Communications Available online at: https://www.usda.gov/media/press-releases/2015/09/16/ usda-and-epa-join-private-sector-charitable-organizations-set (accessed June 15, 2021). 
USDA Economic Research Service (2013). 2013 Rural-Urban Continuum Codes. Available online at: https://www.ers.usda.gov/ data-products/rural-urban-continuum-codes.aspx (accessed August 4, 2021).

USDA ERS (2019). Key Statistics and Graphics. USDA Economic Research Service. Available online at: https://www.ers.usda.gov/topics/food-nutritionassistance/food-security-in-the-us/key-statistics-graphics.aspx (accessed August 9, 2021).

Wheeler, T., and von Braun, J. (2013). Climate change impacts on global food security. Science 341, 508-513. doi: 10.1126/science. 1239402

Willett, W., Rockström, J., Loken, B., Springmann, M., Lang, T., Vermeulen, S., et al. (2019). Food in the anthropocene: the EAT-Lancet Commission on healthy diets from sustainable food systems. Lancet 393, 447-492. doi: 10.1016/S0140-6736(18)31788-4

Author Disclaimer: The content is solely the responsibility of the authors and does not necessarily represent the official views of the National Institutes of Health and the National Science Foundation.
Conflict of Interest: The authors declare that the research was conducted in the absence of any commercial or financial relationships that could be construed as a potential conflict of interest.

Publisher's Note: All claims expressed in this article are solely those of the authors and do not necessarily represent those of their affiliated organizations, or those of the publisher, the editors and the reviewers. Any product that may be evaluated in this article, or claim that may be made by its manufacturer, is not guaranteed or endorsed by the publisher.

Copyright $\odot 2021$ Ahmed, Stewart, Smith, Warne and Byker Shanks. This is an open-access article distributed under the terms of the Creative Commons Attribution License (CC BY). The use, distribution or reproduction in other forums is permitted, provided the original author(s) and the copyright owner(s) are credited and that the original publication in this journal is cited, in accordance with accepted academic practice. No use, distribution or reproduction is permitted which does not comply with these terms. 